\section{Bone and joint}

\section{infection}

Tony Berendt BM BCh FRCP, Consultant Physician

Ivor Byren MB ChB FRCP, Consultant

Physician

Bone Infection Unit, Nuffield Orthopaedic Centre, Oxford

Clin Med 2004;4:510-18

Bone and joint infections, though uncommon, cause serious morbidity and pose significant management challenges. They may cause permanent disability, paralysis and, rarely, death. Their management can be challenging for many doctors, mainly due to unfamiliarity and a poor evidence base. For effective management, well coordinated multidisciplinary working is important. ${ }^{1}$

\section{General considerations}

Pathogens access bones and joints via haematogenous spread or direct inoculation from a contiguous focus of infection (see Ref 2 for review). Injury to bone facilitates infection, possibly by exposure of extracellular matrix proteins to which many organisms, especially staphylococci, can adhere. Infection is also more likely in the presence of biomaterials, which in this context include not only the metal and plastic involved in a prosthetic joint but also acrylic bone cement, devascularised bone graft and synthetic bone substitutes. All these non-vital materials cause local immune impairment and allow nonpathogenic skin commensals such as coagulase-negative staphylococci to become significant pathogens. Table 1 summarises the manifestations, microbiology and presentation of bone and joint infections.

Musculoskeletal infection leads to inflammatory responses that trigger bone resorption, cartilage destruction and bone death (through thrombosis and disruption of the blood vessels supplying bone). Dead bone then behaves in the same way as foreign material; providing an inanimate surface to which microorganisms adhere, adopting a phenotype relatively resistant to both phagocytosis and antibiotics. ${ }^{3}$ As a result, chronically established orthopaedic infection can be remarkably persistent or evolve even in the face of prolonged antibiotic therapy.

In contrast to subacute and chronic infections, which usually have abnormal plain radiology, acute infections usually have no radiographic changes at presentation as it takes at least 7-10 days for detectable bone loss or periosteal reaction to develop. However, scans to detect bone oedema or collections in soft tissue are valuable, with magnetic resonance imaging (MRI) the scanning of choice for native bone. For metalware-associated infection, no scanning methodology has a standardised and well-evaluated performance. Diagnostic techniques are discussed further in Table 2, and Figs 1-5 illustrate the appearances of commonly performed diagnostic investigations.

Antibiotic treatment should, when possible, be based on the results of cultures from good quality specimens taken from deep tissues. Cultures are still subject to problems of contamination and reduced sensitivity, especially in chronic conditions. Molecular methods on aspirates or biopsies offer promise but are still experimental in individual centres. It is usually prudent to begin empiric treatment in acute infections of native joint and bone; this is much less commonly necessary in chronic or implant-related infection unless the presentation suggests bacteraemia or necrotising soft tissue infection. Duration, choice and route of administration remain largely nonevidence based, ${ }^{4}$ but the regimen should include a drug active against Staphylococcus aureus. Where oral agents are used in preference to intravenous therapy, the antibiotic(s) chosen must be highly bioavailable (see Table 3 ). It is advisable to seek advice from a microbiologist or infectious diseases specialist.

Surgery is frequently required as an accompaniment to antibiotics. In acute infections, the presence of an abscess, necrosis, wound dehiscence or failure to respond to appropriate therapy are all indications for surgery. In chronic infections, surgery is invariably required for radical cure of infection. It is also indicated for intolerable pain, drainage, functional impairment or chronic systemic illness.

\section{Specific conditions}

\section{Acute septic arthritis and osteomyelitis}

Acute septic arthritis and osteomyelitis are usually haematogenous in origin, but in rare cases the former complicates arthrocentesis or arthroscopy. Haematogenous infections are in decline in the Northern hemisphere; ${ }^{5}$ rates are higher in the Southern hemisphere, particularly among socially less advantaged ethnic groups.

Both conditions present with high fever and constitutional upset, and 50\% of cases have an accompanying bacteraemia. Pain and loss of function are striking, accompanied by swelling,

\section{Key Points}

Physicians should be alert to the possibility of musculoskeletal infection because of its destructive potential

Acute presentations are emergencies due to the potential for permanent skeletal damage and the development of chronic infection

Chronic infections rarely require urgent management or empirical therapy provided the patient remains well

Chronic ulcers and wounds should be inspected with careful consideration of their relationships to underlying bone or implants

KEY WORDS: arthroplasty, bone infection, osteomyelitis, septic arthritis 
warmth and joint irritability or bony tenderness. Erythema suggests bursitis accompanying septic arthritis or tracking of a subperiosteal abscess from bone into the soft tissues, but its absence does not rule out deep infection.

\section{Diagnosis}

Diagnosis should be made on clinical grounds with the results of investigations used to confirm the diagnosis. Treatment should not be delayed while awaiting the results of confirmation tests. Obtaining cultures of blood, synovial fluid or direct aspirate of bone (the latter is possible in neonates and infants) is an essential element of good practice; if positive, it enables certainty in antibiotic choice. Joint aspirates can diagnose alternatives to infection such as haemarthrosis, gout or pseudogout, but the gram-stain has limited sensitivity compared with culture so cannot rule out infection of a joint affected by gout or pseudogout.

Plain films may show soft tissue swelling or an effusion; only in subacute or acute-on-chronic osteomyelitis will bone destruction or periosteal reaction be present. MRI is the confirmatory test of choice for acute osteomyelitis. In children, ultrasound can demonstrate periosteal elevation; in all age groups it can show soft tissue oedema, abscess and joint effusion, and guide aspiration of the joint.

\section{Treatment}

Time is of the essence once the diagnosis has been considered. Cure rates for acute septic arthritis and osteomyelitis are high provided neither bone death nor joint damage has occurred but fall dramatically if these events take place. Treatment should commence with intravenous antibiotics active against beta-haemolytic streptococci and staphylococci including, where appropriate risk factors exist, methicillin-resistant $S$. aureus (MRSA). The prevalence of community-acquired MRSA strains is currently increasing in
North America and Australia. ${ }^{6}$ These strains appear to be biologically successful and commonly cause severe soft tissue infection, complicated by musculoskeletal involvement in some cases. Although gram-negative organisms are uncommon pathogens in this context, the serious consequences of inadequate treatment justify inclusion of anti-gram-negative cover in the initial regimen chosen.

\section{Surgery}

If the diagnosis is suspected, an orthopaedic opinion should be sought. Surgical exploration is not routinely necessary in acute osteomyelitis (indications for surgery have been discussed above). In acute septic arthritis in children, 'medical' therapy is a well-established mode of treatment for joints accessible to daily aspiration, reserving arthrotomy for joints that fail to settle after five days of treatment. The exception is the hip and the shoulder which can hold large volumes of pus. The circulation to the

Table 1. Manifestations of bone and joint infection.

\begin{tabular}{|c|c|c|c|}
\hline History & Structure infected & Microbiology & Seen by: \\
\hline \multirow[t]{8}{*}{ Acute } & Joint: & & \\
\hline & Native & SA, BHS, aGNR, Gc, Pn & $\mathrm{P} ; \mathrm{O} ; \mathrm{M} ; \mathrm{R}$ \\
\hline & Prosthetic & SA, BHS CoNS, aGNR; E & $\mathrm{O}$ \\
\hline & Bone: & & \\
\hline & Spine & SA, aGNR, PA & $\mathrm{M} ; \mathrm{O} ; \mathrm{R}$ \\
\hline & Long bones & SA, BHS & $\mathrm{O} ; \mathrm{P}$ \\
\hline & $\begin{array}{l}\text { Any bone following insertion of } \\
\text { metalware }\end{array}$ & SA, BHS, CoNS, aGNR & $\mathrm{O}$ \\
\hline & Following open fracture & As above and aGPR, PA, anO & \\
\hline \multirow[t]{12}{*}{ Chronic } & Joint: & & \\
\hline & Native & MTB, SS, SA & R; O; M \\
\hline & Prosthetic & CoNS, SA, aGNR, E & 0 \\
\hline & Bone: & & \\
\hline & All sites & $\begin{array}{l}\text { Original organism when treatment for acute } \\
\text { osteomyelitis fails }\end{array}$ & $\mathrm{O}$ \\
\hline & Spine & SA, aGNR, PA, MTB, B & M; O; R \\
\hline & Long bones & SA, CoNS, aGNR, PA & 0 \\
\hline & Foot bones & SA, BHS, aGNR & $\mathrm{M} ; \mathrm{O} ; \mathrm{D} ; \mathrm{N}$ \\
\hline & & $\mathrm{PA}$ & 0 \\
\hline & Sternum, ribs & SA, aGNR, PA & $\mathrm{Ct} ; \mathrm{C} ; \mathrm{M}$ \\
\hline & Pelvis, trochanter, calcaneus & $\mathrm{SA}, \mathrm{aGNR}, \mathrm{anO}{ }_{2}, \mathrm{PA}, \mathrm{E}$ & M \\
\hline & Skull & SA, aGNR & ENT; NS \\
\hline
\end{tabular}

Pathogens: aGNR = aerobic gram-negative rods; $\mathrm{anO}_{2}=$ anaerobes; $\mathrm{B}=$ Brucella spp; $\mathrm{BHS}=$ beta-haemolytic streptococcus; CoNS = coagulase-negative staphylococcus; $\mathrm{E}=$ enterococci; $\mathrm{Gc}=$ gonococcus; $\mathrm{MTB}=$ Mycobacterium tuberculosis; $\mathrm{PA}=$ Pseudomonas aeruginosa; $\mathrm{Pn}=$ pneumococcus; $\mathrm{SA}=$ Staphylococcus aureus; SS = Sporothrix schenkii.

Specialists: $C=$ cardiologist; $C t=$ cardiothoracic surgeon; $D=$ diabetologist; $E N T=$ ear, nose and throat surgeon; $M=$ general physician; $N=$ nephrologist; $\mathrm{NS}=$ neurosurgeon; $\mathrm{O}=$ orthopaedic surgeon; $\mathrm{P}=$ paediatrician; $\mathrm{R}=$ rheumatologist. 
femoral and humeral heads is vulnerable to high intra-articular pressure, so arthrotomy or arthroscopic washout is the standard of care.

In adults, orthopaedic surgeons usually advise washout for all acutely infected joints unless the patient is unfit for anaesthetic. Arthroscopic washout, unlike arthrotomy, is well tolerated and provides a means to inspect articular cartilage, remove debris and obtain diagnostic tissue samples.

Duration of antibiotic treatment depends upon clinical circumstances, host biology and microbiological considerations (Table 4). Duration of treatment regimens in children with uncomplicated disease is falling. ${ }^{7,8}$

For both conditions, failure to respond within 48-72 hours of onset of appropriate antibiotic therapy should prompt re-evaluation for a surgical focus using appropriate scans. If the patient remains systemically unwell, the possibility of additional foci, including a distant focus such as endocarditis, must also be considered. Septic arthritis is polyarticular in $5 \%$ of presentations, usually occurring in compromised hosts and carrying a high mortality.

\section{Rehabilitation}

Speed of rehabilitation tends to be dictated principally by pain, loss of joint mobility or surgical issues. There is no benefit in enforced rest or restrictions of function. Prognosis is generally good when presentation is prompt and empiric treatment started early. With delay of either, the likelihood of bone or cartilage destruction increases, which itself leads to chronicity, long-term disturbances of growth or function and the need for surgery.

\section{Unusual sites of infection}

Most infections involve the large joints and the metaphyses of the long bones adjoining them. Unusual localisations of infection that are almost always first seen by the general physician are infections in the sterno-clavicular, costo-chondral or manubrio-sternal joints, usually presenting with atypical chest pain. Aspiration, biopsy or drainage may be required for these joints as for any other.

\section{Chronic osteomyelitis}

There is no formal consensus definition of chronic osteomyelitis as compared

Table 2. Diagnostic tests in bone and joint infection.

\begin{tabular}{|c|c|c|}
\hline Test & Role & Problems and confounders \\
\hline ESR, CRP, WBC & $\begin{array}{l}\text { Non-specific supportive evidence; useful for serial } \\
\text { monitoring if initially elevated }\end{array}$ & Lack of specificity \\
\hline Blood cultures & Culture pathogen & Only useful in acute infection; sensitivity $30-60 \%$ \\
\hline Plain film & $\begin{array}{l}\text { Show soft tissue swelling; effusion; arthritis; bone } \\
\text { destruction; periosteal reaction; sclerosis; loosening } \\
\text { of metalware or prosthetic joint; exclude fracture or } \\
\text { tumour }\end{array}$ & $\begin{array}{l}\text { Lag time for development of changes; minimum } \\
10 \text { days in acute infection, loosening of hardware, } \\
\text { many weeks; in diabetic foot, neuro-osteoarthropathy } \\
\text { (Charcot) }\end{array}$ \\
\hline Ultrasound & $\begin{array}{l}\text { Distinguish effusion from synovitis; haematoma; } \\
\text { collection; sinus tract; periosteal elevation; soft tissue } \\
\text { oedema and abscess; permits aspiration/biopsy }\end{array}$ & Technical expertise and available equipment \\
\hline Arthrogram & Loosening; permits aspiration of synovial fluid & $\begin{array}{l}\text { Prosthetic joint only; technical expertise; changes seen } \\
\text { are rarely specific for infective loosening }\end{array}$ \\
\hline Sinogram & Communication of sinus with bone or joint & Technically difficult; may be painful; low sensitivity \\
\hline${ }^{99} \mathrm{Tc}-B o n e$ scan & Show osteoblastic reaction to bone pathology & $\begin{array}{l}\text { Sensitive but non-specific; rarely distinguishes } \\
\text { infection from other pathology }\end{array}$ \\
\hline White cell scan & Inflammation including within bone & $\begin{array}{l}\text { Low sensitivity; must usually combine with other } \\
\text { isotope scans }\end{array}$ \\
\hline MRI & $\begin{array}{l}\text { Intraosseous and soft tissue oedema; cortical } \\
\text { destruction; abscess formation; spinal cord/nerve } \\
\text { root anatomy; extent and surgical planning }\end{array}$ & $\begin{array}{l}\text { Degradation of image quality by artefact from } \\
\text { metalware even if removed; slow to normalise after } \\
\text { infection or surgery; pacemakers; claustrophobia with } \\
\text { most scanners }\end{array}$ \\
\hline Joint aspirate & $\begin{array}{l}\text { Exclude haemarthrosis, gout and pseudogout; } \\
\text { analysis for gram-stain, polymorphs, culture }\end{array}$ & $\begin{array}{l}\text { Technical expertise for some joints; synovitis may } \\
\text { block needle or be misinterpreted as effusion }\end{array}$ \\
\hline $\begin{array}{l}\text { Bone or synovial } \\
\text { biopsy }\end{array}$ & Culture and histology (see below) & $\begin{array}{l}\text { Technical expertise; need ultrasound or fluoroscopic } \\
\text { guidance; sampling error }\end{array}$ \\
\hline \multirow[t]{2}{*}{ Operative sample } & Culture of pathogen & $\begin{array}{l}\text { Prior antibiotics; for chronic infections, may need } \\
\text { enhanced culture methods }\end{array}$ \\
\hline & $\begin{array}{l}\text { Histology: acute, chronic or granulomatous } \\
\text { inflammation; tumour; necrosis; crystals }\end{array}$ & $\begin{array}{l}\text { Sampling error; few specialist osteoarticular } \\
\text { histopathologists }\end{array}$ \\
\hline PCR of sample & Highly sensitive for pathogen detection & Still in development \\
\hline
\end{tabular}

$\mathrm{CRP}=\mathrm{C}$-reactive protein; $\mathrm{ESR}=$ erythrocyte sedimentation rate; $\mathrm{MRI}=$ magnetic resonance imaging; $\mathrm{PCR}=$ polymerase chain reaction; $\mathrm{WBC}=$ white blood cell count 


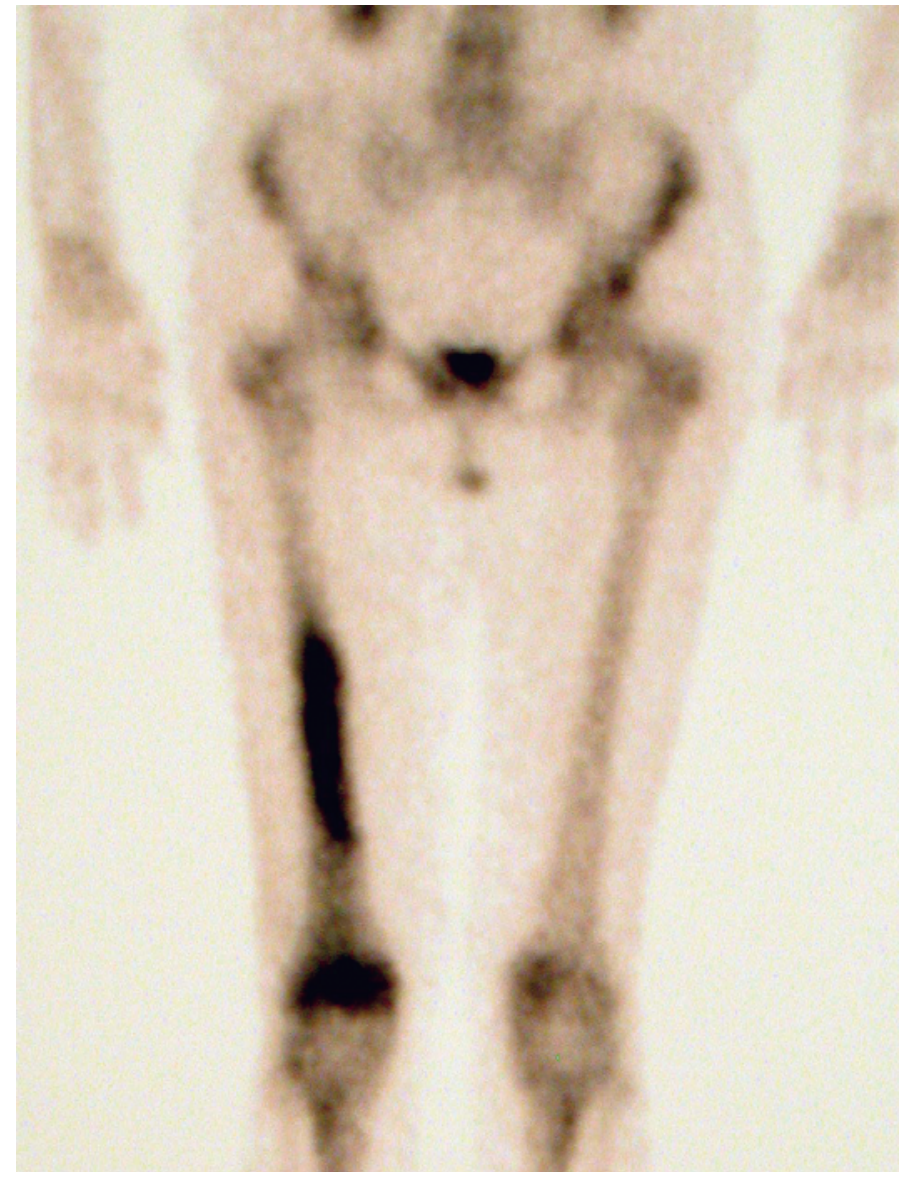

Fig 1. ${ }^{99} \mathrm{Tc}$ bone scan showing high signal in femoral canal and distal metaphysis in a case of chronic osteomyelitis of the femur. Bone scan is no longer recommended in view of its poor specificity.

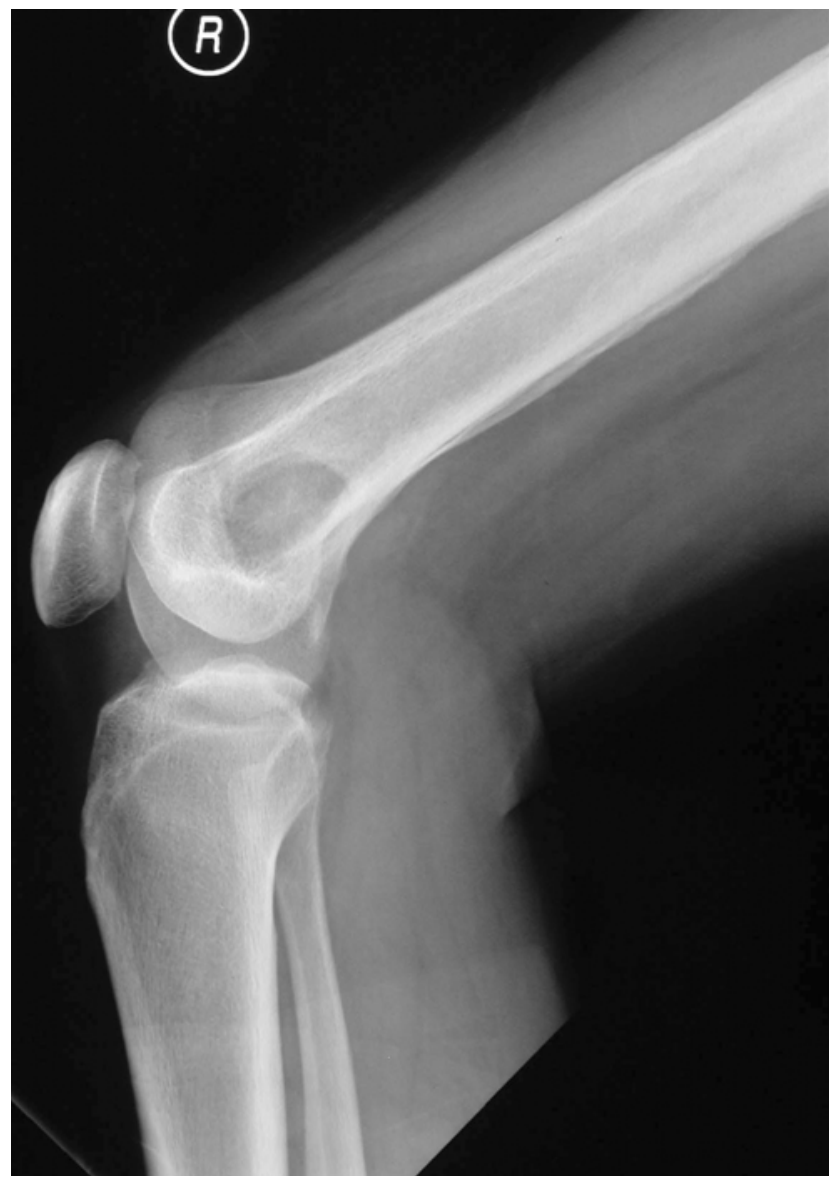

Fig 2. Plain radiograph of the same case, showing cavity in the femoral condyle and chronic periosteal reaction extending up the shaft of the femur. with acute. Most authorities consider that the presence of dead bone transforms the prognosis and is therefore the defining characteristic.

\section{Long-bone osteomyelitis}

Chronic long-bone osteomyelitis is usually preceded by an infected fracture fixation or a complicated acute osteomyelitis. Outside highly specialised units, the physician is likely to be involved in such cases only if medical complications of therapy or comorbidities require management. Venous ulceration virtually never leads to osteomyelitis except when there is visible or palpable exposed bone. In the absence of these features, we believe plain films 'to exclude osteomyelitis' are not usually indicated.

Advanced techniques now exist in specialist centres for managing established chronic long-bone osteomyelitis.
These include use of:

- external Ilizarov ring fixators and bone transplant or vascularised free fibular grafts for the management of large segmental bone defects, and

- free muscle flaps for filling large soft tissue defects.

Both permit more aggressive resection of dead and infected bone and unhealthy soft tissue. The days of curettage of osteomyelitic bone blindly through a sinus or a minimal bone resection using an incision through an old scar should be over.

The physician may need to take the primary role, with surgical help, in three specific situations:

- vertebral osteomyelitis

- osteomyelitis underlying decubitus ulcers (pressure sores)

- osteomyelitis in the diabetic foot.

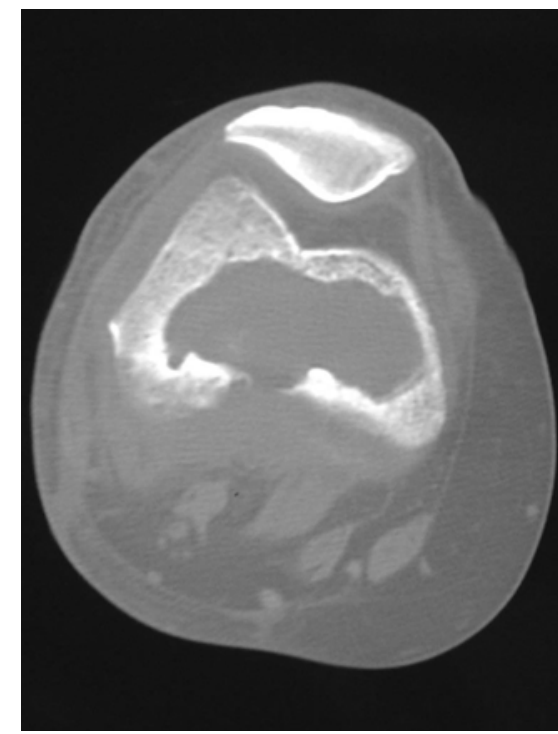

Fig 3. Computed tomography scan of the same case, showing large cavity within femoral condyle and a posterior cortical breach (this patient had a draining sinus). 


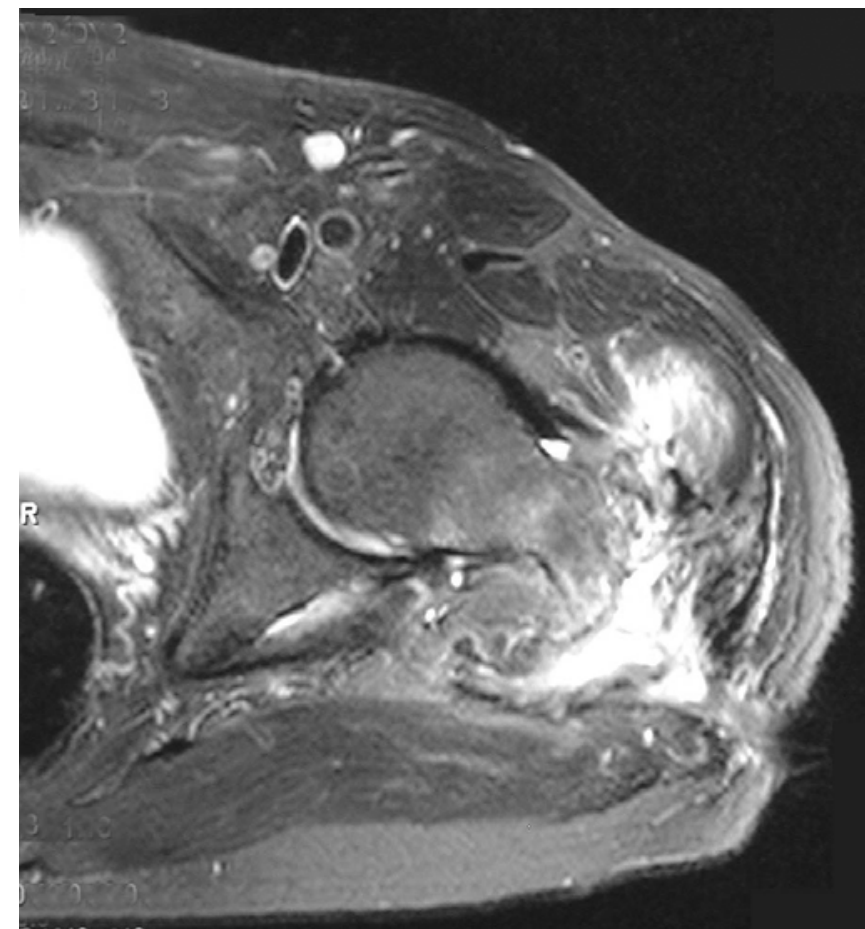

Fig 4, above. Magnetic resonance scan of a different patient showing inflammatory mass, bony oedema, soft tissue collection and sinus tract in a case of chronic trochanteric bursitis and proximal femoral osteomyelitis.

Fig 5, right. Plain radiograph of hip with chronic infection following hip replacement. The hip replacement has been removed but there is retained cement in the femur and metalware which needs to be removed to make arrest of infection likely.

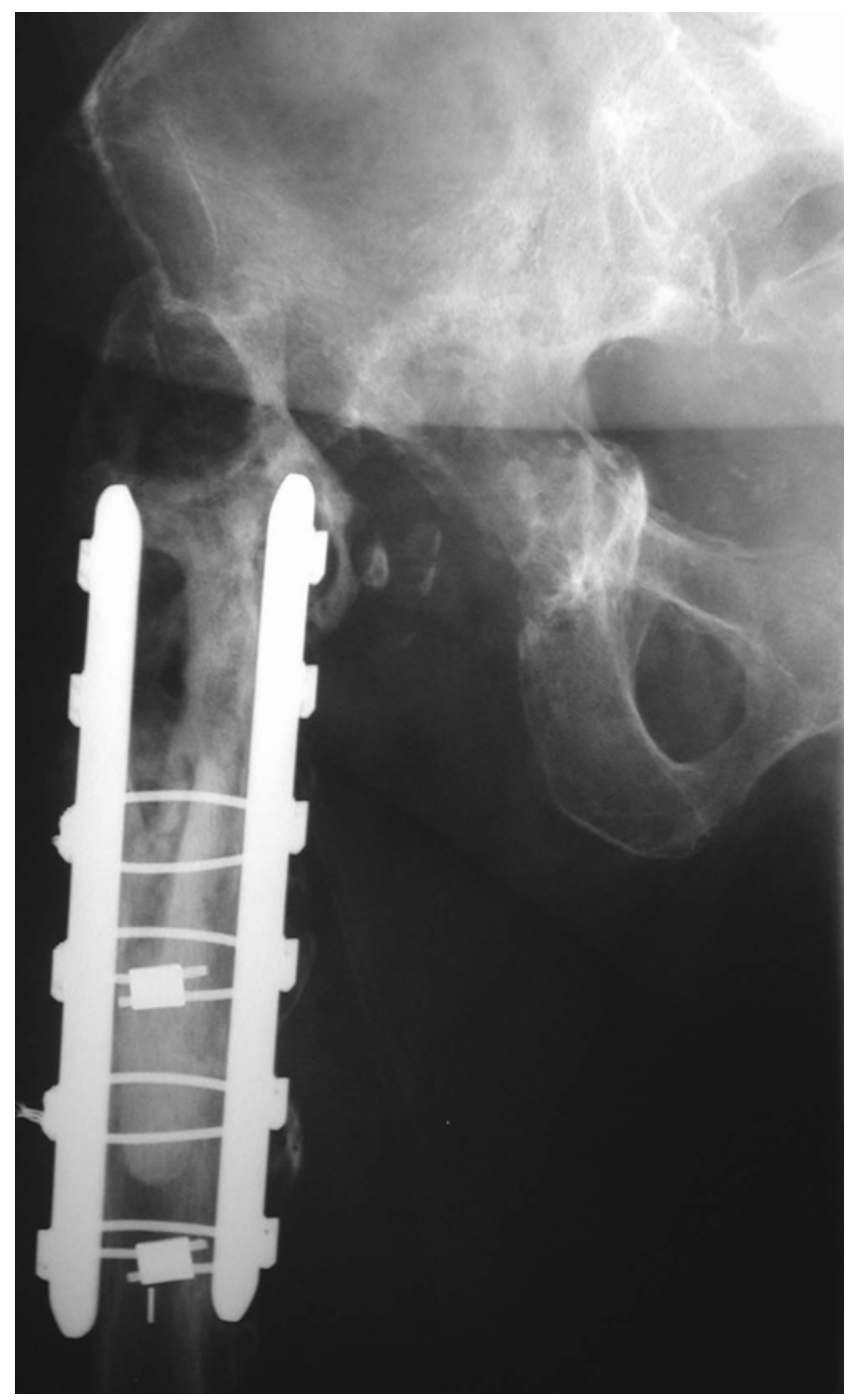

\section{Vertebral osteomyelitis}

The incidence of vertebral osteomyelitis is rising, probably in tandem with increasing numbers of elderly patients with degenerate spinal pathology and risk factors for bacteraemia. ${ }^{9}$ After S. aureus (including MRSA), aerobic gram-negative rods such as Escherichia coli are the next most common pathogen, it is believed from urinary or gastrointestinal sources. The presentation is with severe back pain, especially at night, at rest and on movement. Referred pain in a radicular pattern can give confusing presentations with abdominal or thoracic pain. The presentation may be insidious and without fever, but it is essential to remember that severe acute back pain with fever followed by the development of neurological symptoms and signs is a medical emergency. These symptoms are highly suggestive of a spinal epidural abscess, for which urgent imaging and surgery is indicated (after antibiotics have commenced).

Back pain is common in elderly hospitalised patients and may be ignored at first, while an elevated erythrocyte sedimentation rate and anaemia of chronic disease may lead only to a search for metastasis or myeloma. Plain films classically show loss of disc space and erosion of end plates, but are not recommended in the evaluation of back pain because of poor sensitivity. MRI is the investigation of choice; if contraindicated, spiral computed tomography (CT) will show paraspinal soft tissue swelling or abscess and also allow evaluation of the vertebral bodies, end plates and disc space. Blood cultures may be positive early in the disease but are usually negative in chronic presentations. Biopsy of an infected disc space or paraspinal tissue is a useful means of obtaining tissue for microbiology and histology. Cultures should be sent for tuberculosis (TB) and Brucella spp where risk factors exist.

Many cases of spinal osteomyelitis can be treated with antibiotics alone. Surgery is indicated for spinal cord compression, abscess formation, persistent pain, progressive deformity and recurrence after adequate treatment. Recovery is generally good, with back pain resolving in 2-4 weeks. If paralysis has developed, it is likely to resolve in TB. The outlook is guarded in pyogenic infections, with paralysis due to spinal epidural abscess carrying a particularly poor prognosis because of spinal cord infarction. 


\section{Associated with decubitus ulcers}

Osteomyelitis complicating decubitus ulcers exemplifies the 'contiguous focus' route of infection. S. aureus continues to play an important role, but these infections are more likely to be polymicrobial and derived from the mixed colonising flora of the ulcer or wound overlying the bone.

Osteomyelitis of this type also illustrates that, once underlying bone is infected, wound healing will not occur unless the deep infection is resolved. The result is a vicious circle of soft tissue loss, bone death, spreading infection and further soft tissue loss. It is essential to target the pathogens and the dead bone, address the soft tissue cover, reconstructing it where possible, and to remove the factors that led to its initial breakdown. Recurrence is almost inevitable unless the following action is taken:

- appropriate wound care

- pressure offloading

- avoidance of wound contamination with faeces or urine, and

- attention to metabolic, endocrine and nutritional derangements.

Presentation may be with a nonhealing pressure sore or with an acute soft tissue infection and/or systemic illness due to a flare in activity. Plain films show bone destruction, but these can be difficult to interpret in the common locations (sacrum, ischium, trochanter and calcaneum). CT shows bone destruction more reliably and will also show associated intra- or extrapelvic

Table 3. Useful antibiotics in bone and joint infection.

Bioavailability of oral preparation

\begin{tabular}{|c|c|c|c|}
\hline \multirow[b]{2}{*}{ Antibiotic } & \multirow[b]{2}{*}{ Intravenous } & \\
\hline & & High & Nil, poor or variable \\
\hline Penicillin & Yes & & Yes \\
\hline Amoxicillin & Yes & Yes & \\
\hline Flucloxacillin & Yes & & Yes \\
\hline Cefalexin/Cefradine & Yes & Yes & \\
\hline Cefuroxime & Yes & & Yes \\
\hline Ceftriaxone & Yes & & Yes \\
\hline Other cephalosporins & Yes & & Yes \\
\hline Carbapenems & Yes & & Yes \\
\hline Aminoglycosides & Yes & & Yes \\
\hline $\begin{array}{l}\text { Glycopeptides } \\
\text { (Vancomycin and } \\
\text { Teicoplanin) }\end{array}$ & Yes & & Yes \\
\hline Clindamycin & Yes & Yes & \\
\hline Ciprofloxacin & Yes & Yes & \\
\hline Rifampicin & & Yes & \\
\hline Fusidic acid & & Yes & \\
\hline Doxycycline & & Yes & \\
\hline Linezolid & Yes & Yes & \\
\hline $\begin{array}{l}\text { Isoniazid } \\
\text { Pyrazinamide } \\
\text { Ethambutol }\end{array}$ & & Yes & \\
\hline
\end{tabular}

abscesses, while MRI gives more information about the extent of bone involvement. Bone biopsy is recommended for defining causative organisms; surface swabs do not reliably predict the deep pathogens.

\section{In the diabetic foot}

Given the pandemic of type 2 diabetes, osteomyelitis in the diabetic foot is prob- ably now the commonest cause of bone infection worldwide. Although sometimes classified as 'osteomyelitis associated with vascular insufficiency', in most cases neuropathy plays the key role in aetiology. This affects foot biomechanics and impairs protective sensation. The result is repetitive excessive loading on areas of high pressure leading to ulceration. Peripheral vascular disease further accelerates tissue loss, impairs healing in

Table 4. Antibiotic duration in acute osteomyelitis and septic arthritis.

\begin{tabular}{|c|c|c|c|}
\hline Condition & Patient group & Duration & Notes \\
\hline Acute osteomyelitis & $\begin{array}{l}\text { Child } \\
\text { Adult: } \\
\text { normal host } \\
\text { immunocompromised }\end{array}$ & $\begin{array}{l}2-4 \text { weeks } \\
4 \text { weeks } \\
\geq 4 \text { weeks }\end{array}$ & $\begin{array}{l}\text { Short duration assumes no complications requiring } \\
\text { surgery and rapid response } \\
\text { Numerous atypical pathogens identified }\end{array}$ \\
\hline \multirow[t]{2}{*}{ Acute septic arthritis } & $\begin{array}{l}\text { Child } \\
\text { Adult: normal host }\end{array}$ & $\begin{array}{l}2-3 \text { weeks } \\
2-3 \text { weeks }\end{array}$ & $\begin{array}{l}2 \text { weeks: Streptococci, GC; } \\
3 \text { weeks: SA, aGNR }\end{array}$ \\
\hline & $\begin{array}{l}\text { Adult: } \\
\text { immunocompromised (or } \\
\text { abnormal joint, } \\
\text { eg rheumatoid, severe } \\
\text { osteoarthritis) }\end{array}$ & $\geq 4$ weeks & $\begin{array}{l}\text { If exposed bone at time of infection, treat as } \\
\text { presumptive osteomyelitis }\end{array}$ \\
\hline
\end{tabular}

aGNR = aerobic gram-negative rods; GC = Neisseria gonorrhoeae; SA = Staphylococcus aureus. 
some cases and confers a worse prognosis when infection is present.

The distribution of diabetic foot ulceration and associated osteomyelitis is characteristic of the abnormal biomechanics:

- Hyperextension and subluxation at the metatarso-phalangeal joint, with clawing of the toes and exaggeration of the plantar arch, lead to ulcers under the metatarso-phalangeal heads, on the ends of the toes and over the proximal interphalangeal joints.

- Hallux rigidus causes ulcers on the medial side of the interphalangeal joint of the hallux.

- Ischaemia leads to ulceration on the lateral border of the fifth metatarsal and over the calcaneus.

- End-stage mid-foot neuroosteoarthropathy results in collapse of the plantar arch, causing a 'rocker bottom' foot prone to mid-plantar ulceration.

As with decubitus ulcers, the presentation can be indolent or triggered by an acute soft tissue infection. Bacteraemia, abscess, necrotising soft tissue infection or cellulitis can all complicate an ulcer that, if neglected long term, may cause bone involvement.

Osteomyelitis in the diabetic foot should be suspected when a chronic ulcer:

- remains unhealed after 6-8 weeks of adequate debridement and offloading, provided that it is also adequately perfused

- $\quad$ is large and deep

- has bone visible or palpable in its base

- has bone fragments being expelled from it, or

- has evidence of bone destruction beneath it on plain radiographs.

Clinical guidelines. Two recently produced clinical practice guidelines, from the International Consensus on the Diabetic Foot and the Infectious Diseases Society of America, deal with diabetic foot infection including osteomyelitis. ${ }^{10,11}$ Their advice is the following:
1 A standardised approach should be taken to all diabetic patients presenting with an infected foot ulcer to assess the systemic, cognitive and social status of the patient; the vascularity and involvement with infection of the limb and foot; the biomechanics of the foot; and the perfusion, extent, depth, degree of infection and sensation associated with the ulcer. (The acronym PEDIS is a useful mnemonic and also identifies an ulcer classification scheme produced for research purposes. ${ }^{12}$ )

2 Debridement of the ulcer early in assessment, as it is not otherwise possible to determine the extent and depth of involvement. This can often be performed by a podiatrist or other trained specialist. The 'probe to bone' test, in which a sterile metal probe is inserted into the ulcer in search of stony-hard palpable bone, is moderately predictive of osteomyelitis if it is positive. ${ }^{13}$

3 Infection is categorised as 'mild', 'moderate' and 'severe' (Table 5). The severity helps to determine who should be admitted to hospital and how broad-spectrum empiric antibiotic therapy should be. For severe infections, do not delay antibiotic therapy and have a high index of suspicion for surgical complications.

4 When osteomyelitis is suspected, obtain bone biopsy if possible for culture and histology. Biopsy can be performed percutaneously by a radiologist; if surgery is required, the surgeon should discuss microbiological sampling technique with a specialist in infection.

5 Duration of antibiotic therapy can be fixed depending upon the degree of bony resection or debridement (Table 6). If residual infected bone remains, prolonged therapy is advised.

6 Route of administration of antibiotics is less important than ensuring that high serum levels are obtained. Outpatient intravenous antibiotic therapy programmes ${ }^{14}$ or the use of highly bioavailable oral antibiotics reduce the need for prolonged hospitalisation purely for antimicrobial therapy.

As with pressure sore-related osteomyelitis, treatment must be accompanied by measures to optimise wound healing and minimise the risk of recurrence. This is important whether or not surgery is carried out. In some situations, surgery increases the risk of future ulcers by further compromising the biomechanics of the foot, while in several retrospective series $60-80 \%$ of cases eventually resolved with antibiotics and non-surgical wound care, but case selection may be important. There is renewed uncertainty about the relative roles of surgery and 'conservative' therapy in diabetic foot osteomyelitis. ${ }^{15}$

\section{Chronic septic arthritis}

Chronic septic arthritis is relatively uncommon except in relation to prosthetic joints (see below). In addition to missed or incompletely treated acute septic arthritis (mainly due to $S$. aureus and beta-haemolytic streptococci), it may be due to Brucella spp, TB or atypical mycobacteria and to environmental fungi such as Sporothrix schenkii. Presentation is with a chronic monoarthropathy, usually with extensive synovitis, pain, crepitus and accelerated changes on plain X-ray. MRI confirms loss of cartilage, synovitis, effusion and bone changes consistent with chronic infection.

Some microbiological causes (such as $\mathrm{TB})$ are amenable to prolonged antimicrobial treatment alone, although the joint will generally develop accelerated arthritis. In situations where extensive joint destruction has occurred, joint replacement will probably be required, depending upon progress over time. This can be performed either in a single operation with antibiotic-loaded cement or as a staged procedure, debriding the whole joint in the first stage and implanting the prosthesis in the second procedure once infection has been treated. Involvement of a specialist in joint reconstruction with appropriate microbiological/infectious diseases support is advised. 


\section{Infections of prosthetic joints and other orthopaedic metalware}

While usually the sole province of the surgeon, these problems may occasionally present to the physician as a bacteraemia at any stage of the lifetime of the joint. Acute presentations may be accompanied either by local symptoms of acute wound infection if very early in the life of the implant or by acute septic arthritis involving the prosthetic joint if infection occurs later. Most chronic infections present with sinus tract drainage from the prosthetic joint and/or progressive pain due to mechanical loosening. Sinus tract drainage usually commences with what appears to be a boil or a granuloma in the old surgical incision or a drain site. Any such lesion overlying hardware should raise the suspicion of deep infection. Loosening presents with progressive pain which, until there is gross loosening, has the character of 'start up' pain that eases off with joint motion. Often, the patient will say that the implant has 'never felt right', a vague, but surprisingly consistent complaint.

Loosening of prostheses causes painful loss of function. Other orthopaedic metalware is used to stabilise fractures or fusion procedures, so loosening of these implants causes instability and an increased risk of non-union or failed fusion.

\section{Treatment}

Treatment strategies depend on whether the implant has a permanent or temporary function. If temporary, and the func- tion is completed (eg the fracture has united), the implant can be removed and the bone debrided as for chronic osteomyelitis. If union or fusion has not yet occurred and the implant is temporary, the choice of treatment depends upon the mechanical state of the implant. If it is still soundly fixed to bone, and infection has presented early or the patient is not suitable for surgery, retention of the implant can be attempted. A surgical debridement of surrounding soft tissue is undertaken, a microbiological diagnosis established and specific antibiotics commenced. In acute infections, it is possible to salvage the implant in over $50 \%$ of cases with a combination of urgent surgery and prolonged, culturedirected antibiotics. Combinations of a fluoroquinolone (ciprofloxacin or ofloxacin) and rifampicin seem to be of

Table 5. Categories of diabetic foot infection, as defined by the International Consensus on the Diabetic Foot and the Infectious Diseases Society of America, Clinical Practice Guideline.

\begin{tabular}{|c|c|c|c|c|c|}
\hline Severity & $\begin{array}{l}\text { PEDIS } \\
\text { grade }\end{array}$ & Risk & Manifestations & Pathogen & Antibiotics \\
\hline Mild & 2 & Minimal & $\begin{array}{l}0.5-2 \mathrm{~cm} \text { erythema; } \\
\text { superficial ulceration; } \\
\text { systemically well }\end{array}$ & $\begin{array}{l}\text { SA } \\
\text { BHS }\end{array}$ & $\begin{array}{l}\text { Flucloxacillin } \\
\text { Cefalexin } \\
\text { Clindamycin } \\
\text { Co-amoxyclav }\end{array}$ \\
\hline Moderate & 3 & Limb & $\begin{array}{l}>2 \mathrm{~cm} \text { erythema } \\
\text { Involvement beneath fascia of } \\
\text { bone, joint, tendon sheath, } \\
\text { subcutaneous tissues; gangrene, } \\
\text { necrosis } \\
\text { NO SYSTEMIC TOXICITY }\end{array}$ & $\begin{array}{l}\text { SA } \\
\text { BHS } \\
\text { aGNR }\end{array}$ & $\begin{array}{l}\text { Co-amoxyclav } \\
\text { Ciprofloxacin }+ \\
\text { Clindamycin }\end{array}$ \\
\hline Severe & 4 & Life and $\operatorname{limb}$ & $\begin{array}{l}\text { Any manifestation of infection } \\
\text { with systemic illness and fever } \\
\text { OR critical limb ischaemia }\end{array}$ & $\begin{array}{l}\mathrm{SA} \\
\mathrm{BHS} \\
\text { aGNR } \\
\mathrm{anO}_{2} \\
\mathrm{PA}\end{array}$ & $\begin{array}{l}\text { Cefuroxime }+ \\
\text { Metronidazole }+ \\
\text { Gentamicin } \\
\text { Carbapenem } \\
\text { Piperacillin }+ \\
\text { Tazobactam ADD } \\
\text { Vancomycin for MRSA }\end{array}$ \\
\hline
\end{tabular}

aGNR = aerobic Gram-negative rods; $\mathrm{anO}_{2}=$ anaerobes; $\mathrm{BHS}=$ beta-haemolytic streptococcus; MRSA = methacillin-resistant Staphylococcus aureus; PA = Pseudomonas aeruginosa; PEDIS = perfusion, extent, depth, degree of infection and sensation associated with the ulcer; SA = Staphylococcus aureus. NB. PEDIS Grade 1 is a clinically uninfected ulcer.

Table 6. Duration of antibiotic therapy for diabetic foot osteomyelitis, as advised by the International Consensus on the Diabetic Foot and the Infectious Diseases Society of America, Clinical Practice Guideline.

Bone involvement after debridement

Entire involved bone removed

Viable remnant of infected bone remains

Dead infected bone remains

\section{Soft tissue involvement after debridement}

No remaining infected soft tissue

Residual soft tissue infection

Residual soft tissue infection or none
Duration of therapy

2-3 days
$7-14$ days
4-6 weeks

$\geq 3$ months (suppressive therapy) 
particular value in the treatment of sensitive staphylococci (the most common pathogen). ${ }^{16}$

Physicians may encounter these patients on long-term antibiotics presenting with drug side effects or more commonly with coincidental medical problems. Antibiotics should not be stopped in this situation without consultation with a consultant in microbiology or infectious diseases as, even after prolonged treatment, recurrence can occur when antibiotics are withdrawn. ${ }^{17}$

In well-established infections implant salvage is rarely successful, with or without surgery. Aspiration or biopsy of the joint can be helpful in confirming the diagnosis, but may give a false-negative result. It is usually necessary to remove the infected hardware and replace it either immediately or in a second stage (operation) after antibiotic treatment. With this approach, cure rates of $95 \%$ have been achieved in some series.

\section{Conclusions}

The evidence base for practice in bone and joint infection remains weak, but a level of good practice can none the less be defined. This involves:

- careful consideration of bone and joint infection as a possible diagnosis in appropriate presentations

- the systematic cultivation of good working relationships between physicians and surgeons

- careful microbiological sampling to direct targeted antibiotic therapy and, above all,

- surgical excellence in both judgement and technique.

Despite the key role of the surgeon in many cases, physicians still have important skills to bring to a team approach. They are comfortable managing multiple comorbidities, polypharmacy and chronic diseases and also the accompanying psychological and rehabilitation issues. We hope this article will allow the informed physician to engage more effectively with surgeons and patients in the pursuit of improved outcomes from these potentially devastating conditions.

\section{References}

1 Ziran BH, Rao N, Hall RA. A dedicated team approach enhances outcomes of osteomyelitis treatment. Clin Orthop 2003 Sep (414):31-6.

2 Mandal S, Berendt AR, Peacock SJ. Staphylococcus aureus bone and joint infection. Review. J Infect 2002;44:143-51.

3 Costerton JW, Stewart PS, Greenberg EP. Bacterial biofilms: a common cause of persistent infections. Review. Science 1999;284: 1318-22.

4 Stengel D, Bauwens K, Sehouli J, Ekkernkamp A, Porzsolt F. Systematic review and meta-analysis of antibiotic therapy for bone and joint infections. Review. Lancet Infect Dis 2001;1:175-88.

5 Blyth MJ, Kincaid R, Craigen MA, Bennet GC. The changing epidemiology of acute and subacute haematogenous osteomyelitis in children. J Bone Joint Surg Br 2001;83: 99-102.

6 Vandenesch F, Naimi T, Enright MC, Lina G et al. Community-acquired methicillinresistant Staphylococcus aureus carrying Panton-Valentine leukocidin genes: worldwide emergence. Emerg Infect Dis 2003;9: 978-84.

7 Jaberi FM, Shahcheraghi GH, Ahadzadeh M. Short-term intravenous antibiotic treatment of acute hematogenous bone and joint infection in children: a prospective randomized trial. J Pediatr Orthop 2002;22:317-20.

8 Le Saux N, Howard A, Barrowman NJ, Gaboury I et al. Shorter courses of parenteral antibiotic therapy do not appear to influence response rates for children with acute hematogenous osteomyelitis: a systematic review. BMC Infect Dis 2002; 2:16.

9 Jensen AG, Espersen F, Skinhoj P, Rosdahl VT, Frimodt-Moller N. Increasing frequency of vertebral osteomyelitis following Staphylococcus aureus bacteraemia in Denmark 1980-1990. J Infect 1997;34: 113-8.

10 Lipsky BA, Berendt AR, Deery HG, Embil JM et al. Diagnosis and treatment of diabetic foot infections. Clin Infect Dis 2004; 39:885-910.

11 Lipksy BA, Berendt AR, Embil J, De Lalla F. Diagnosing and treating diabetic foot infections. Diabetes Metab Res Rev 2004; 20(Suppl 1):S56-64.

12 Schaper NC. Diabetic foot ulcer classification system for research purposes: a progress report on criteria for including patients in research studies. Diabetes Metab Res Rev 2004;20(Suppl 1):S90-5.

13 Grayson ML, Gibbons GW, Balogh K, Levin E, Karchmer AW. Probing to bone in infected pedal ulcers. A clinical sign of underlying osteomyelitis in diabetic patients. JAMA 1995;273:721-3.

14 Tice AD, Hoaglund PA, Shoultz DA. Outcomes of osteomyelitis among patients treated with outpatient parenteral antimicrobial therapy. Am J Med 2003;114:723-8.

15 Jeffcoate WJ, Lipsky BA. Controversies in diagnosing and managing osteomyelitis of the foot in diabetes. Clin Infect Dis 2004; 39(Suppl 2):S115-22.

16 Zimmerli W, Widmer AF, Blatter M, Frei R, Ochsner PE. Role of rifampin for treatment of orthopedic implant-related staphylococcal infections: a randomized controlled trial. Foreign-Body Infection (FBI) Study Group. JAMA 1998;279:1537-41.

17 Segreti J, Nelson JA, Trenholme GM. Prolonged suppressive antibiotic therapy for infected orthopedic prostheses. Clin Infect Dis 1998;27:711-3. 